\title{
Demandas de atenção de um paciente na unidade de transplante de medula óssea*
}

\author{
DEMANDS FOR ATTENTION EXPERIENCED BY APATIENT \\ INABONE MARROW TRANSPLANTS UNIT
}

\author{
DEMANDAS DE ATENCIÓN VIVENCIADAS POR UN PACIENTE \\ EN UNA UNIDAD DE TRANSPLANTE DE MEDULA ÓSEA
}

Letícia Pontes', Edinêis de Brito Guirardello², Claudinei José Gomes Campos ${ }^{3}$

* Extraído da disser-
tação "Demandas de
Atenção Dirigida em
pacientes submetidos
a transplante de
Medula Óssea",
Faculdade de Ciên-
cias Médicas da
Universidade Esta-
dual de Campinas
(FCM-UNICAMP),
2004.
1 Enfermeira. Mestre
em Enfermagem.
Professora do Curso
de Enfermagem da
Pontifícia Universidade
Católica do Paraná -
Campus Toledo.
leticia.pontes@
pucpr.br
2 Enfermeira. Professora
Doutora do Departa-
mento de Enfermagem
da FCM-UNICAMP.
guirar@fcm.unicamp.br
3 Enfermeiro. Doutor
em Ciências
Médicas/Saúde
Mental. Professor
Colaborador do
Departamento de
Enfermagem da
FCM-UNICAMP.
cjcampos@
fcm.unicamp.br

\section{RESUMO}

A capacidade de direcionar atenção é essencial para o funcionamento efetivo da vida diária, pois permite a pessoa manter atividade intencionada, apesar de distrações do ambiente. Este estudo de abordagem qualitativa teve como objetivo identificar as demandas de atenção vivenciadas por um paciente portador de leucemia mielóide aguda, submetido a Transplante de Medula Óssea (TMO), seguindo o referencial teórico de atenção e demandas de atenção. Os dados foram obtidos por meio de entrevista semi-estruturada e observação assistemática, com posterior análise de conteúdo temático. Os resultados apontaram que o paciente em TMO está exposto a muitas demandas de atenção, como: ausência da família, o medo da morte, incerteza do futuro, espaço físico restrito, afastamento do trabalho, excesso de manuseio da equipe de enfermagem, entre outras.

\section{DESCRITORES}

Leucemia mielóide.

Transplante de medula óssea. Atenção.

\section{ABSTRACT}

The capacity to focus attention is essential for the effective handling of everyday life for it allows one to perceive, think clearly and keep the intended activity in course despite environmental distractions. This qualitative approached study was aimed at identifying the attention demands experienced by a patient diagnosed with sharp myeloid leukemia submitted to a bone marrow transplants (BMT) following the theoretical reference of attention and attention demands. The data was collected through a semi-structured interview and a-systematic observation, with later content thematic analysis. The results pointed out that the patient in BMT lives multiple attention demands, such as: absence of family, fear of death, uncertainty about the future, restricted physical space, removal from work and too much handling by the Nursing staff, among others.

\section{KEY WORDS}

Leukemia myeloid.

Bone marrow transplant.

Attention.

\section{RESUMEN}

La capacidad de orientar la atención es esencial para el funcionamiento efectivo de la vida diaria, pues permite a la persona mantener una actividad intencional, a pesar de distraccio-nes del ambiente. Este estudio de abordaje cualitativo tuvo como objetivo identificar las demandas de atención vivenciadas por un paciente portador de leucemia mieloide aguda sometido a Transplante de Médula Ósea (TMO), siguiendo el referencial teórico de atención y demandas de atención. Los datos fueron obtenidos por medio de una entrevista semi estructurada y observación asistemática, con posterior análisis de contenido temático. Los resultados señalaron que el paciente en TMO está expuesto a muchas demandas de atención, como: ausencia de la familia, el miedo a la muerte, incertidumbre por el futuro, espacio físico restringido, alejamiento del trabajo, exceso de manipulación del equipo de enfermería, entre otras.

\section{DESCRIPTORES}

Leucemia mieloide.

Transplante de medula ósea.

Atención. 


\section{INTRODUÇÃO}

O câncer configura-se como a segunda causa de morte por doença no Brasil e a cada ano surgem, aproximadamente, 400 mil novos casos ${ }^{(1)}$. É uma doença que, além da gravidade aliada às crenças ao desconhecimento quanto ao seu prognóstico e tratamento, faz com que as pessoas a vejam como aterrorizadora e incurável.

Dentre os tipos de câncer, a leucemia tem sido objeto de atenção dos profissionais de saúde, talvez por atingir uma população jovem que se encontra no auge da sua fase produtiva e resultar em alto índice de mortalidade.

As leucemias estão classificadas em agudas e crônicas, estando divididas em mieloblástica e linfocítica e suas subclassificações. A leucemia mieloblástica aguda (LMA) caracteriza-se pela rápida instalação e progressão da doença, resultando em $100 \%$ de mortalidade dentro de dias ou meses, quando não tratada adequadamente ${ }^{(2)} \mathrm{e}$, por isso, causa maiores preocupações. cessa e organiza uma informação importante. É necessária para o funcionamento efetivo da vida diária, pois permite à pessoa perceber, pensar com clareza e manter atividade intencionada, apesar de distrações ${ }^{(6-7)}$.

O uso intenso e prolongado da CDA pode levar a pessoa a desenvolver fadiga de atenção, caracterizada pela condição de desconforto e redução da efetividade ${ }^{(8)}$. Uma pessoa com fadiga de atenção apresenta uma diminuição ou incapacidade de direcionar a atenção $0^{(9)}$ e pode apresentar essa dificuldade para resolver problemas, planejar, fazer uma atividade proposta ou monitorar seu comportamento ${ }^{(6)}$.

Durante as fases de diagnóstico e tratamento de uma doença que ameaça a vida, tal como o câncer, fatores afetivos, comportamentais e de informação aumentam as exigências para o uso da CDA em períodos prolongados. Fatores afetivos, como incerteza sobre o futuro e pensamentos dolorosos, associados a perdas reais ou antecipadas, podem agir como distrações contínuas que interferem na participação das atividades propostas ${ }^{(6)}$.
O transplante de medula óssea (TMO), inicialmente utilizado como última medida terapêutica, hoje é considerado uma forma de terapia bem sucedida para determinadas doenças habitualmente fatais, como a leucemia ${ }^{(3)}$.

O TMO é um processo complexo, longo e agressivo, portanto, não está isento de complicações que, por vezes, deixam lesões ou têm conseqüências fatais. Os pacientes vivenciam experiências muito dolorosas, tanto de ordem física quanto psicológica.

Durante o processo de TMO, os pacientes passam por um sistema diferente de internação, em relação ao tempo, necessidade de isolamento, protocolo rígido de rotinas, além da previsão das reações e efeitos colaterais que o tratamento provoca. Em estudo com adolescentes submetidos a TMO, observou-se que esses pacientes vivenciam muita dor e sofrimento, pois quando o paciente chega a uma unidade de TMO, normalmente, já possui uma bagagem de vivência de tratamento, exames e buscas que antecedem à concretização do transplante propriamente dito ${ }^{(4)}$.

A expectativa do que vai acontecer, da dor, das mudanças na rotina diária e das alterações físicas as quais terá que se submeter provocam um sofrimento por antecipação, deixando-os mais fragilizados, resultando, assim, em um aumento da capacidade de direcionar atenção (CDA) para lidar com essas demandas.

A CDA é um tipo de atenção seletiva, originalmente, referida como atenção voluntária ${ }^{(5)}$. É a habilidade que a pessoa tem em inibir estímulos e distrações competitivas, tanto do ambiente interno como do externo, enquanto pro-
As demandas de atenção referem-se a fatores que aumentam a necessidade de direcionar atenção, ou seja, levam ao aumento do uso da $\mathrm{CDA}^{(7)}$. Mas, o simples fato de prestar atenção envolve um processo neurocognitivo complexo, exigindo do paciente esforço mental e, quanto maior for o número de demandas, maior é o esforço ${ }^{(7)}$. Esse esforço, quando intenso e prolongado, pode levar à fadiga de atenção, dificultando o manejo das atividades do dia a dia ${ }^{(8)}$.

Portanto, o conhecimento das demandas de atenção vivenciadas por pacientes com leucemia mielóide aguda e submetidos à TMO, torna-se imprescindível para que o profissional de saúde, em especial o enfermeiro possa planejar uma assistência direcionada às necessidades do paciente. Outrossim, verifica-se a inexistência de estudos que abordem os fatores de demandas de atenção a que os pacientes com leucemia e submetidos ao transplante de medula óssea vivenciam.

\section{OBJETIVO}

O presente estudo teve como objetivo identificar as demandas de atenção vivenciadas pelo paciente em uma unidade de transplante de medula óssea.

\section{TRAJETÓRIA METODOLÓGICA}

Para desenvolver este estudo foi utilizada a metodologia qualitativa, especificamente, o método de estudo de caso. $\mathrm{O}$ estudo de caso envolve a análise de um caso, que pode ser 
simples ou específico, complexo ou abstrato, devendo ser sempre bem delimitado. Tem como objetivo compreender, de forma singular, uma experiência vivenciada pelo sujeito. Para os autores, o caso pode caracterizar-se por uma instituição, um evento, um grupo ou uma pessoa ${ }^{(10)}$.

O cenário de investigação deste estudo foi uma unidade de transplante de medula óssea de um hospital universitário, localizado no sul do Brasil. Os dados foram coletados após aprovação do Comitê de ética em pesquisa da Faculdade de Ciências Médicas da UNICAMP (Processo n 578/2002).

O sujeito do estudo foi um paciente do sexo masculino, com 34 anos de idade, com leucemia mielóide aguda (LMA) e submetido à TMO do tipo alogênico, com doador não aparentado. Este participou voluntariamente da investigação, após obtenção do consentimento livre e esclarecido.

Para a obtenção dos dados, utilizou-se a técnica de entrevista semi-estruturada e a observação assistemática. A entrevista semi-estruturada foi gravada em áudio, com duração de 90 minutos, realizada por um dos pesquisadores, após o consentimento explícito do sujeito, seguindo um roteiro pré-estabelecido.

A coleta de dados ocorreu no quarto de internação do sujeito, no $27^{\circ}$ dia pós-transplante, três dias antes da alta hospitalar. A coleta de dados ocorreu neste período por considerar-se este o melhor momento para a obtenção dos dados, tendo em vista que o sujeito se encontrava em condições de ser submetido ao procedimento da entrevista e de já ter vivenciado fases importantes do processo de tratamento, como a espera pelo transplante, período de condicionamento, infusão da medula óssea e a fase da pega do enxerto.

Após a entrevista, foi realizada a transcrição literal da mesma, acrescida da descrição da linguagem não verbal, passando por mais de uma revisão, de modo, a garantir sua fidedignidade.

Para a análise dos dados, utilizou-se a análise de conteúdo temática ${ }^{(11)}$. Como parte dos procedimentos de análise realizou-se uma leitura exaustiva do material. Posteriormente, foram destacados fragmentos do texto, denominados unidades de análise, recortes esses que passaram por um tratamento gramatical, com intuito de refinamento literário, sem, contudo, modificar o teor da mensagem emitida pelo entrevistado. Na categorização dos dados, foi levado em consideração a freqüência no aparecimento dos temas, bem como a sua relevância implícita.

\section{Procedimentos Relativos à Categorização}

Inicialmente, para a categorização dos dados considerou-se como categoria, à priori, os domínios afetivo, de informação, físico-ambiental e comportamental, já descritos e conceituados ${ }^{(12)}$.
O domínio afetivo refere-se às emoções ou sentimentos vivenciados pela pessoa, incluindo preocupação e medo, além de sentimentos, como: raiva, tristeza, esperança, desesperança, alegria, solidão, dor, impotência entre outros.

O domínio físico-ambiental refere-se a fatores do ambiente externo e seu uso, incluindo tudo a que está diretamente relacionado: objetos, espaço físico, temperatura, luminosidade, equipamentos, som e movimentos, assim como o funcionamento do ambiente, ou seja, a sua atmosfera.

O domínio de informação refere-se a fatores que interferem na percepção e interpretação da informação e fazem com que a informação seja inadequada, não familiar ou muito sufocante.

O domínio comportamental refere-se a fatores, como: afastamento do convívio social, obediência a normas e expectativas sociais que restringe a pessoa a comportamentos necessários, abandono do trabalho e de atividades de lazer. Este domínio também compreende as mudanças de situações induzidas que requerem alteração no estilo de vida.

Em decorrência da riqueza e profundidade das experiências relatadas pelo entrevistado, criou-se algumas subcategorias para uma melhor compreensão dos tipos de demandas vivenciados pelo mesmo, a partir dos recortes da entrevista, entendido como mais significativos para os domínios analisados.

\section{ANÁLISE E DISCUSSÃO DOS RESULTADOS}

Os dados obtidos, por meio da entrevista, evidenciaram a riqueza e a profundidade da experiência desse paciente durante o processo de tratamento numa unidade de medula óssea.

As categorias e subcategorias estão apresentadas de forma didática, conforme se dá no cotidiano do paciente em TMO. Constatou-se, no decorrer da análise, uma interação entre os domínios, trazendo algumas dificuldades na classificação das categorias e subcategorias.

\section{Domínio afetivo}

No domínio afetivo, pela sua subjetividade, as demandas de atenção emergiram de diversas formas e de modo significativo nas falas do entrevistado. Foram expressas com emoção, desde a dor da perda ao sentimento da esperança e da fé, coisas difíceis de mensurar, mas possíveis de perceber diante da expressão do olhar ou da força da palavra.

As subcategorias identificadas como demandas de atenção, vivenciadas pelo paciente e relacionadas a este domínio, foram: ausência da família; medo da morte; incerteza do futuro e sentimento de compaixão. Essas demandas exigi- 
ram dele uso intenso e prolongado de esforço mental para direcionar atenção a aspectos importantes do tratamento como, por exemplo: compreender uma informação.

A ausência da família foi referida pelo paciente como a demanda que mais lhe exigiu esforço mental. Enfatizou que ficar longe das filhas foi mais difícil do que suportar outros aspectos difíceis do tratamento, conforme suas falas no início da entrevista e ao término da gravação respectivamente:

\begin{abstract}
Eu acho que o PIOR de tudo, que eu digo assim oh! Eu sou muito... eu tenho duas filhas né, então o pior pra mim é me afastar delas! ... eu acho que, a PIOR coisa daqui nem é o mal estar, o físico, mas eu acho que é a distância de repente que fica.

... o mais importante de tudo, é o que eu vou te dizer agora: A PIOR COISA! O pior de TUDO AQUI é ficar longe da minha família. NADA É PIOR DO QUE ISSO!
\end{abstract}

A família configura-se pelo parentesco e pelas relações íntimas, ao carinho, afeição e apoio, bem como pela participação mútua em várias atividades e interesses. Quando um, ou mais membros da família está ausente, esta pode ser considerada incompleta ou quebrada ${ }^{(13)}$.

O profissional de saúde, em especial, o enfermeiro, ao prestar assistência pode, pelo cultivo da sensibilidade, oferecer um relacionamento interpessoal mais afetivo ${ }^{(14)}$ minimizando a ausência da família. A qualidade dessa relação depende da competência do profissional e de sua habilidade em estabelecer relacionamentos interpessoais adequados no processo do cuidar ${ }^{(15)}$

O medo da morte foi identificado no conteúdo da entrevista por meio de expressões subjetivas, sendo que o entrevistado não mencionou a palavra morte na sua forma direta durante todo o encontro com o pesquisador. Para esse paciente não ter a garantia de cura da doença, fez brotar o sentimento de que o amanhã pode não existir, conforme pode ser observado na seguinte fala:

\begin{abstract}
... o problema é o seguinte: se tu vai fazer um tratamento que a pessoa vai te dizer assim... vai ficar parado três meses em casa, é uma coisa! Só que aqui tu não tem prazo de validade! ... ninguém vai te dizer assim oh! Uma margem, eles te dão um percentual (de sobrevida)!
\end{abstract}

Este paciente, adulto jovem, pode estar vivendo um dos períodos mais importantes da vida humana. Esta é uma fase da vida em que não somente as decisões mais importantes são tomadas, mas também a fase mais criativa do homem. A possibilidade da morte faz com que o indivíduo sinta que pode perder, o que Freud diz ser de máxima importância para o homem, o amor e o trabalho ${ }^{(16)}$. Isto pode constituir em uma demanda de atenção, pois exige do paciente o uso de esforço mental para direcionar atenção para outros aspectos importantes do tratamento, bem como para determinar objetivos de sua vida.
A incerteza do futuro constitui em mais uma demanda para o paciente, pois aponta para uma preocupação num futuro mais distante, sugerindo que a esperança existe para esse paciente. A possibilidade de sucesso no tratamento pode trazer para o paciente sentimentos diversos, bons ou de incertezas, fazendo com que mais essa demanda de atenção esteja presente. Como será sua vida após a cura, também traz sentimento de agonia, como é explicitada na fala a seguir:

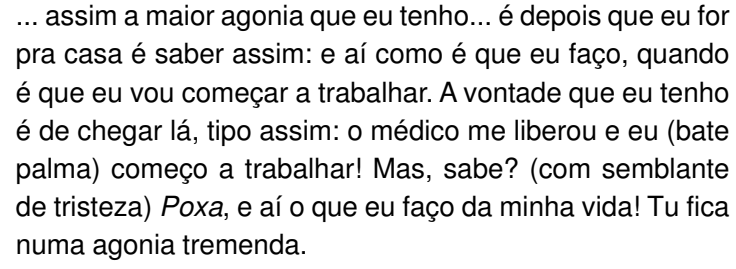

O sentimento de impotência frente à doença e a cobrança social de produtividade nesta fase pode resultar em baixa auto-estima para a pessoa. Fatores afetivos como incerteza do futuro e pensamentos dolorosos, associados a perdas reais ou antecipadas, podem agir como distrações contínuas que interferem na participação das atividades $\operatorname{propostas}^{(6)}$.

É importante perceber que o exercício de colocar esses sentimentos em suspensão implica uma certa desarticulação do individuo em sua vivência em relação à doença, e, à medida que as demandas de atenção necessitam de um descolamento entre a realidade vivida de forma angustiante e uma outra realidade, ou seja, a necessidade de focar atenção nos próprios cuidados a sua condição de saúde.

O sentimento de compaixão também foi identificado como uma demanda de atenção. O entrevistado enfatizou sobre o seu sofrimento diante da angústia expressa por outro paciente quanto à insegurança e despreparo ao receber informações sobre as possíveis complicações do tratamento, que fazem parte do protocolo daquela unidade. Esse sentimento de impotência diante do outro, pode exigir do mesmo o uso de esforço mental desviando a atenção para a resolução de seus próprios problemas. Este sentimento pode ser vislumbrado a partir do seguinte recorte:

E aí que nem eu tava falando pra um rapaz que esteve aqui pra conversar comigo, estava apavorado... E ele falou: é me deram um papel pra mim ler lá e não sei o que, é um horror de coisa que pode acontecer. Aí eu disse não, tu tem que pensar uma coisa: se tu for lê aquilo ali e vai achar que vai acontecer tudo aquilo ali... tu rasga e vai pra casa e não faz mais nada. Aí ele diz assim: o que é que eu faço? Eu olhei pra ele e disse assim: cara, quer saber de uma coisa? Esquece! Esquece, esquece não fica ti estressando com isso aí, não fica te... te metendo na cabeça que pode dar isso, que pode dar aquilo, porque não sei o que, porque... isso não vai te ajudar em nada... Eu disse pra ele... digo tu esquece isso aí e vou te dizer uma coisa... digo reza... falei pra ele. Tu quer saber de uma coisa? REZA! 
Nesse domínio, houve um predomínio de demandas em relação aos demais domínios investigados, identificando o maior número de demandas de atenção vivenciadas durante o processo de tratamento. Esse resultado é relevante, considerando-se que a área afetiva influencia diretamente no processo de aprendizagem do indivíduo. Conseqüentemente, pode haver um declínio na sua capacidade de direcionar atenção para aspectos importantes do tratamento.

Este aspecto aparece presente no paciente que, dessa forma, só consegue direcionar sua atenção para pensamentos incertos (perda, abandono), podendo encontrar dificuldades para absorver novas informações ou atividades propostas ${ }^{(6)}$.

A atitude de certo acolhimento visto no processo de identificação do problema do outro, pelo próprio paciente, define de alguma forma a importância deste comportamento, pois, percebe-se a necessidade de proximidade entre eles, não só como possibilidade de escuta, mas também como ponto de apoio e alento. Esse movimento pode ser realizado pelo profissional de enfermagem criando, assim, vertentes que possibilitam minimizar ansiedades e proporcionar uma melhora na capacidade de direcionar atenção (CDA).

\section{Domínio informação}

Neste domínio, as informações em seu conteúdo e forma apareceram como fator de demanda de atenção. Estas demandas estão relacionadas à percepção e interpretação das informações recebidas, explicitadas nas subcategorias: informações imprecisas e excesso de informações.

A imprecisão de informação exigiu grande esforço mental para o entrevistado. A teoria do cuidar de Watson enfatiza a promoção de ensino-aprendizagem interpessoal como fator importante para o processo de cuidar ${ }^{(14)}$. Conforme referencial teórico já estudado, esta demanda também pode servir como fonte de distração contínua, pois pode impedir a pessoa de focar a atenção para outras informações importantes. Na fala apresentada abaixo, é possível perceber como uma informação imprecisa pode constituir-se em uma fonte de demanda de atenção.

... quando eu vim pra fazer o transplante, fiquei e ainda estou, muito assustado com isso ... quando eu internei com a doença, quando foi feito o diagnóstico, parecia uma coisa assim oh: que a princípio SÓ a quimioterapia cura, mas se tu fizer o auto-transplante quase 100\% garantido... Então tu imagina assim: bom, só com a quimioterapia já é quase certo, faz um auto tem $80 \%$, BELEZA! E aí te dá uma recaída e aí te dizem assim: bom, agora é $50 \%$ se tu tiver em remissão, e aí tu não tá em remissão! $\mathrm{E}$ aí te dizem assim: bom agora, infelizmente é 40\%. PUXA VIDA! ... aí te dão aquele papel com o que PODE acontecer de intercorrências, tá?

O excesso de informações também foi identificado como uma demanda de atenção, à medida que apresentava exces- so de detalhes, muitas vezes, com conteúdo de difícil entendimento. Para esse paciente talvez fosse necessário apenas saber se sua evolução estava sendo favorável, como mostra na sua fala abaixo:

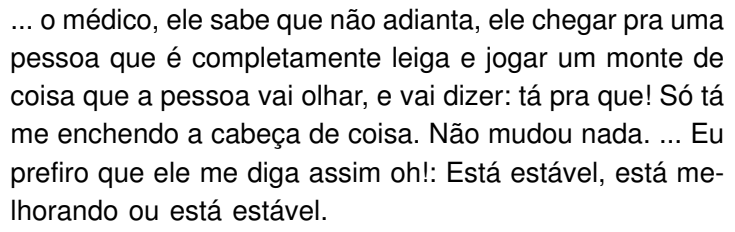
pessoa que é completamente leiga e jogar um monte de coisa que a pessoa vai olhar, e vai dizer: tá pra que! Só tá me enchendo a cabeça de coisa. Não mudou nada. ... Eu prefiro que ele me diga assim oh!: Está estável, está meIhorando ou está estável.

Em estudo realizado com pacientes submetidos a TMO, foi verificado que os pacientes diferem em termos de necessidade de informação sobre o processo de TMO. Alguns sentem estar preparados e adequadamente informados para essa experiência e, eventualmente, solicitam conhecimento e informações adicionais. Entretanto, nem todos os pacientes desejavam obter informações completas sobre o processo de $\mathrm{TMO}^{(17)}$.

Acredita-se que a informação seja um elemento importante para os pacientes submetidos ao TMO, porém, quando claras e objetivas e, talvez, de forma mais coloquial, mais participativa.

A comunicação parece ser aqui um elemento possível de constituir-se em instrumento terapêutico se bem utilizado, uma vez que pode ser um fator de demanda de atenção. $\mathrm{O}$ enfermeiro, pela sua proximidade com o paciente, pode criar estratégias de comunicação que facilitem o entendimento das suas distorções.

\section{Domínio físico-ambiental}

As demandas de atenção relacionadas a este domínio destacaram-se nas falas do entrevistado, por meio das subcategorias: espaço restrito; excesso de manuseio; interrupção do sono.

O espaço físico restrito foi identificado como uma demanda de atenção, vivenciada pelo paciente, num período de recuperação do mesmo. A ausência de um lugar para o paciente realizar atividades como uma simples caminhada, faz com que o mesmo não tenha acesso a pequenas coisas que poderiam lhe proporcionar prazer e ajudar na manutenção da sua capacidade de direcionar atenção. A fala a seguir mostra esta necessidade:

\footnotetext{
... tem uma fase aqui dentro do tratamento que tu está querendo é ficar quieto no quarto. Só que tem uma fase daqui um pouco que tu começa a ti recuperar, e aí tu quer dar uma saidinha, tu quer dar uma caminhada. Só que não tem aonde.
}

Para manter ou recuperar a capacidade de direcionar atenção de uma pessoa é necessário promover um ambiente que capture a atenção involuntária ${ }^{(8)}$. Portanto, proporcionar ao 
paciente um ambiente em que possa fazer uso da atenção involuntária através de experiências com ambientes naturais como jardins, árvores e uma vista natural pode favorecer na manutenção ou na recuperação da capacidade para direcionar atenção ${ }^{(18)}$.

O excesso de manuseio também foi identificado como uma demanda de atenção para este paciente, devida à frequiência a que era submetido a procedimentos de cuidados. Para ele, tais procedimentos não permitiam que pudesse descansar como expressa na seguinte fala:

É CANSATIVO, porque tu fica, que nem eu que fiz a TBI, que é a rádio total. ENTÃO, começa cansando já no primeiro dia que tu entra! Porque é três vezes por dia, fracionada, aquela função que vai lá (a fala sugere muita distância) no outro hospital longe e volta. Isso é horrível! Então é cansativo, fisicamente é cansativo. NOSSA! A primeira fase é estressante... começa com a rádio, e aí tu chega e é aquela correria, é a medicação que tem pra correr (aponta para o suporte de soro e para o cateter), e não dá tempo e é toda hora gente entrando pra troca de medicação, faz isso faz aquilo, e tu não descansa um minuto. Tu não descansa um minuto. De noite, é a noite inteira!

O repouso é essencial para a saúde e, nesse caso, é muitas vezes interrompido. Por isso, o enfermeiro deve estar atento às diferentes fontes de demandas inerentes ao próprio ambiente de uma unidade de TMO, de maneira a utilizarse de estratégias que possam minimizá-las. E é necessário que ele saiba lidar com a alta demanda de atenção em ambientes de cuidados de saúde ${ }^{(7)}$, pois muitas demandas de atenção inerentes ao processo do TMO são inevitáveis, mas dados os efeitos severos da fadiga de atenção, a que esses pacientes estão predispostos, o desenvolvimento de intervenções de enfermagem focadas na melhoria da capacidade de direcionar atenção pode ter alto valor terapêutico.

Um dos fatores da Teoria de Watson sobre o cuidar é a provisão de um ambiente mental, físico, sócio-cultural e espiritual sustentador e protetor ${ }^{(14)}$. Ou seja, que proporcione ao paciente tranqüilidade, repouso e minimize desconforto e promova o descanso mental.

A interrupção do sono, outra demanda de atenção vivenciada por este paciente, é expressa como algo que lhe exigiu esforço mental intenso por período prolongado considerando-se que o mesmo já estava internado há mais de 30 dias. Isso pode ser observado quando relata a dificuldade para dormir durante o processo de tratamento na unidade de TMO:

... durante o dia em vez de, eu pelo menos, ao em vez de eu pegar de repente e dar uma dormida durante o dia eu não dormia, ficava batendo papo com eles (as visitas). Só que cansa pra CARAMBA! Aí de noite quando tu pensa que tu vai (pende o corpo para o lado e fecha os olhos), aí já entra um e já entra outro e faz isso e faz medicação (faz movimentos com as mãos em direção ao cateter e ao suporte de soro) É cansativo MESMO!
O sono constitui uma necessidade humana básica, para o bem estar do indivíduo e deve ser respeitado durante todo o processo de tratamento. Estudos sobre a qualidade de vida de pacientes submetidos a TMO mostraram que o distúrbio do sono era mais intenso após a segunda semana de internação, quando comparado com o período pré-transplante e duas semanas após a alta hospitalar ${ }^{(17)}$.

Destaca-se aqui a importância de o enfermeiro prover cuidados ao paciente, de modo a permitir que o mesmo tenha suas necessidades de sono atendidas, minimizando assim as demandas de atenção que o mesmo vivencia no cotidiano de uma unidade de TMO.

As demandas de atenção identificadas no domínio físico-ambiental, também são relevantes, uma vez que estão relacionadas diretamente a outros domínios. A invasão do seu espaço territorial, a interrupção do seu biorritmo, assim como a exigência de novos hábitos, pode constituir em demandas de atenção por período prolongado. E, talvez, seja neste domínio que o enfermeiro possa dar uma maior contribuição.

\section{Domínio Comportamental}

No domínio comportamental, o afastamento do trabalho parece ter sido uma demanda que exigiu grande esforço mental para este paciente focar atenção a outros aspectos durante o processo de tratamento. Não poder realizar as atividades das quais estava habituado antes do aparecimento da doença, e isso faz o paciente sentir-se inválido. Durante a entrevista o paciente demonstrou várias vezes o sentimento de angústia que esta demanda lhe provoca, como pode ser observado na seguinte fala:

\section{O problema é o seguinte ... eu não tive atividade nenhuma na realidade depois que eu adoeci. Faz dois anos que eu não trabalho.}

Eu não consegui mais trabalhar, e eu tinha uma atividade muito intensa quando trabalhava, trabalhava bastante pra caramba. Então assim oh! É... bah era HORRÍVEL! De repente tu fica inválido, né?

O trabalho para este entrevistado foi lembrado como algo significativo em sua vida, confirmando o valor que se cultua ao trabalho nas sociedades modernas e a necessidade do mesmo para a realização pessoal e financeira dos indivíduos. No caso deste entrevistado, em plena idade produtiva e provedor de família isso parece bastante forte.

O afastamento do trabalho pode também ser considerado como uma perda e, desse modo, ser relacionado ao domínio afetivo. 


\section{CONSIDERAÇÕES FINAIS}

A partir dos dados do sujeito participante no estudo, foram identificadas as demandas: ausência da família; medo da morte; incerteza do futuro; sentimento de compaixão; excesso de informações; imprecisão de informações; excesso de manuseio pela equipe de enfermagem; afastamento do trabalho e restrição de espaço físico. Essas demandas estão relacionadas aos domínios, afetivo, físico-ambiental, comportamental e de informação. Esses dados apresentam-se coerentes com os resultados de outros estudos encontrados em literaturas publicadas, embora nenhum deles seja específico ao tema aqui tratado.

O estudo deste caso sugere que o aumento das demandas de atenção é uma realidade na vida dos indivíduos que

\section{REFERÊNCIAS}

1. Instituto Nacional do Câncer (INCA).[homepage na Internet]. Rio de Janeiro; 2007 [citado 2004 jan. 21]. Disponível em: http:/ /www.inca.gov.br/cancer/tipos/leucemia.html

2. Black JM, Matassarin-Jacobs E. Medical surgical nursing: clinical management for continuity of care. $5^{\text {th }}$ ed. Philadelphia: Saunders; 1997.

3. Foerster J. Transplante de medula óssea. In: Lee GR, Bithell TC, Foerster J, Atheus JW, Lukens JN. Wintrobe hematologia clínica. São Paulo: Mande; 1998. p.766-76.

4. Dóro MP. Avaliação funcional dos adolescentes que se submetem a TMO [dissertação].Curitiba: Setor de Ciências Humanas, Letras e Artes, Universidade Federal do Paraná; 2000.

5. James W. The principles of psychology. New York: Dover; 1890.

6. Cimprich B. Attentional fatigue following breast cancer surgery. Res Nurs Health. 1992;15(3):199-207.

7. Jansen DA, Cimprich B. Attentional impairment in persons with multiple sclerosis. J Neurosci Nurs. 1994;26(2):95-102.

8. Kaplan S, Kaplan R. Cognition and environment: functioning in an uncertain world. New York: Praeger; 1983.

9. Cimprich B. Attentional fatigue and restoration in individuals with cancer [thesis]. Michigan: University of Michigan; 1990. vivenciam o diagnóstico e tratamento de doenças que ameaçam a vida, como o transplante de medula óssea em casos de leucemia, exigindo, deles um esforço mental intenso e prolongado no uso da CDA para aspectos importantes do tratamento.

Desta forma, o enfermeiro necessita conhecer as diferentes fontes de demandas de atenção a que esses pacientes estão expostos, já que eles ocupam um papel essencial no processo de cuidar, por isso ele pode atuar de maneira a intervir e implementar estratégias para minimizá-las ou eliminá-las. Uma forma de minimizar essas demandas consiste em alterar ou reconstruir a rotina de trabalho, rever o processo de comunicação e contribuir com a equipe interdisciplinar para as mudanças do ambiente hospitalar.

10. Ludke M, André MEDA. A pesquisa em educação: abordagens qualitativas. São Paulo: EPU; 1986.

11. Bardin L. Análise de conteúdo. Lisboa: Edições 70; 1977.

12. Jansen DA, Keller ML. Identifying the attentional demands perceived by elderly people. Rehabil Nurs. 1998;23(1):12-20.

13. Pikunas J. Desenvolvimento humano. $3^{\mathrm{a}}$ ed. São Paulo: McGraw-Hill; 1979. p. 335-92.

14. Talento B. Jean Watson. In: George JB. Teorias de enfermagem: dos fundamentos à prática profissional. Porto Alegre: Artmed; 2000. p. 253-65.

15. Lak H. A dimensão subjetiva do profissional na humanização da assistência à saúde: uma reflexão. Rev Esc Enferm USP. 2004;38(1):13-20.

16. Rosa M. Psicologia evolutiva: psicologia da idade adulta. $8^{\mathrm{a}} \mathrm{ed}$. Petrópolis: Vozes; 1996.

17. Hacker ED, Ferrans CE. Quality of life immediately after peripheral blood stem cell transplantation. Cancer Nurs. 2003;26(4):12-32.

18. Kaplan R, Kaplan S. The experience of nature: a psychological perspective. New York: Cambridge; 1989. 